\title{
A defesa de um paradoxo: sofrimento impassível segundo Cirilo de Alexandria
}

Karina Andrea Pereira Garcia Coleta

\section{Resumo}

Ao longo do tempo, o estudo do problema do sofrimento humano tem sido abordado em busca de respostas, soluções e entendimento. No entanto, tal tema se reveste de maior complexidade quando se trata de entender a presença do sofrimento no evento da Encarnação. Afinal, quem sofreu: o humano, o divino, ou ambos? A presente comunicação revisita o debate patrístico acerca da noção de impassibilidade divina na Encarnação com vistas a destacar: a função desempenhada pelo referido conceito no pensamento dos Padres e as contribuições de Cirilo de Alexandria para o desenvolvimento teológico do tema. Tal abordagem se desenvolve em três partes. A primeira delas apresenta o enfrentamento, por parte da Tradição, dos obstáculos presentes nos modelos dos que se preocuparam em explicar o envolvimento de Deus na experiência humana e suas implicações - começando pelo Gnosticismo, passando pelo Docetismo, Arianismo e Nestorianismo. A segunda parte expõe os pontos principais envolvidos na proposta de Cirilo. E, finalmente, a última seção conclui apresentando um elenco de considerações acerca das contribuições e limitações da abordagem ciriliana. 
Palavras-chave: Patrística; Sofrimento impassível; Encarnação; Cirilo de Alexandria.

\begin{abstract}
Throughout time, the problem of human suffering has been approached in a quest for answers, solutions, and understanding. However, the issue increases in complexity when it comes to understanding the presence of suffering on Incarnation event. After all, who suffered: the human, the divine, or both? This paper revisits the patristic debate on the notion of divine impassibility on Incarnation in order to highlight: the function performed by the above mentioned concept in Fathers thought and also Cyril of Alexandria contributions to theological development of the issue. Such approach encompasses three parts. The first one presents the way Tradition faced obstacles present in the models which tried to offer an explanation concerning God's involvement in human experience and its implications - starting by Gnosticism, then Docetism, Arianism and Nestorianism. The second part points out the major points of Cyril proposal. Finally, the last one concludes by presenting the contributions and limitations on Cyril's approach.
\end{abstract}

Keywords: Patristic; Impassible suffering; Incarnation; Cyril of Alexandria.

\title{
Introdução
}

O sofrimento consiste na dolorosa e inescapável realidade presente na experiência humana. Para lidar com sua dor, o homem parte em busca de soluções que possam removê-la ou, pelo menos, suavizá-la, ou ainda, que possam explicá-la, apontando para algum tipo de propósito. O problema do sofrimento é de alcance universal e natureza complexa e por isto, em sua carta apostólica Salvifici doloris, o Papa João Paulo II afirma que este é um tema que "exige ser constantemente retomado"1.

A equação "Deus e sofrimento" intriga, provocando objeções e reflexões que se traduzem em estudos mais apurados na tentativa de compreender a atitude divina face ao sofrimento humano. No entanto, a questão se torna ainda mais complexa quando se trata de entender a presença do sofrimento

${ }^{1}$ JOÃO PAULO II, Papa. Carta apostólica Salvifici Doloris, São Paulo, Paulinas, 1988, p.6. 
na Encarnação, afinal quem sofreu: o humano, o divino, ou ambos? Tal discussão não é recente, o desenvolvimento da teologia da Encarnação no período patrístico fez frente aos desafios colocados pelo tratamento do tema. De maneira geral, a Tradição defendeu a imutabilidade e impassibilidade de Deus, embora alguns, mesmo sem abrir mão da ortodoxia, tenham empregado uma linguagem que, à primeira vista parecesse colocá-la em risco. Por outro lado, também houve os que, apesar de constituírem minoria, sustentassem que Deus fosse passível de sofrimento.

A controvérsia atingiu seu ápice e trouxe, no quinto século, para o centro do debate as figuras de Cirilo de Alexandria e Nestório. Aparentemente, conforme será visto mais adiante, Cirilo defendeu o inconciliável: o sofrimento impassível. Os argumentos cirilianos, na visão de seus oponentes, arriscavam enfraquecer a noção da impassibilidade divina². Porém, ele não rompeu com a mentalidade hegemônica presente na Tradição e contribuiu para o desenvolvimento do pensamento teológico diante dos desafios propostos.

O presente trabalho pretende revisitar o debate sobre a impassibilidade divina no que diz respeito à Encarnação sem perder de vista questões como: a função desempenhada pelo conceito de impassibilidade no pensamento dos Padres $^{3}$ e as contribuições de Cirilo para o desenvolvimento teológico do tema.

O percurso realizado para a abordagem do tema envolve três seções. A primeira delas apresenta o enfrentamento, por parte da Tradição, dos obstáculos presentes nos modelos dos que se preocuparam em explicar o envolvimento de Deus na experiência humana e suas implicações - começando pelo Gnosticismo, passando pelo Docetismo, Arianismo e Nestorianismo. A segunda seção expõe os pontos principais envolvidos na proposta de Cirilo de Alexandria. E finalmente, a última parte conclui, apresentando um elenco de considerações acerca das contribuições e limitações da abordagem ciriliana.

\footnotetext{
${ }^{2}$ GAVRILYUK, Paul, The suffering of the impassible God, New York, Oxford University Press, 2004. Esta obra expõe e critica a tendência moderna em atribuir o conceito de impassibilidade divina a uma suposta assimilação acrítica, no período patrístico, do pensamento filosófico grego em detrimento das Escrituras.

${ }^{3}$ Tanto a análise da função da impassibilidade divina quanto a exposição subsequente dos modelos que tentaram responder à tensão presente no evento da Encarnação tiveram como norte a argumentação da obra de Gavrilyuk citada anteriormente.
} 


\section{Desenvolvimento da teologia da Encarnação: os debates que antecederam Cirilo de Alexandria}

Os desafios propostos ao entendimento da fé cristã desempenharam importante papel no desenvolvimento do pensamento teológico e se encontram na gênese do empenho em apresentar as razões da fé, de tornar o crível inteligível. O desafio inicial que demandou uma resposta da fé cristã foi proposto pelo Gnosticismo.

Os gnósticos concebiam a existência de um Pai, um Filho e uma mãe que seria o Espírito. É como se houvesse em Deus um movimento relacional eterno. Esta concepção gnóstica implicou em uma perspectiva antropomórfica no interior da divindade, na atribuição de emoções próprias das relações humanas ao divino. As duas correntes gnósticas destacadas por Lettieri ${ }^{4}$ como principais são a valentiniana e a setiana (ou barbelognóstica), e ambas aludem à queda da parte fraca da divindade, a chamada Sofia. De acordo com os gnósticos valentinianos, ao cair, Sofia morreu e foi crucificada, e este evento revelou Deus que morreu crucificado e padeceu. Desta forma, segundo Lettieri "com a doutrina gnóstica, a discussão toca os grandes temas do cristianismo" ", dentre eles a questão de como se deu, em Jesus, a união do divino e do humano.

Para os primeiros Padres, a impassibilidade divina era algo a ser resguardado, no entanto, isto colocava uma tensão entre a condição impassível de Deus e seu envolvimento no mundo, tensão que ficava ainda mais evidente na Encarnação.

No desenvolvimento do pensamento teológico patrístico acerca desta tensão podem ser destacados três modelos que tentaram, em alguma medida, apresentar uma solução. A conciliação entre a natureza divina em Cristo e as experiências humanas presentes em seu ministério terreno requeria avanço em sua elaboração sem, contudo, negar a impassibilidade.

Cumpre notar, porém, que o conceito de impassibilidade divina tinha um aspecto funcional, o de salvaguardar a divindade e a transcendência do Deus criador, diferenciando-o das divindades passionais pagãs e limitando a atribuição indiscriminada de emoções a Deus. Desta forma, à primeira vista, considerar a impassibilidade divina como qualificador apofático evitaria o estranhamento que a atribuição de emoções humanas a Deus pudesse causar,

\footnotetext{
${ }^{4}$ LETTIERI, Gaetano. Deus patiens: l'essenza cristologica dello gnosticismo. Lo gnosticismo, le sue origini cristiani e la sua importanza nello sviluppo teológico del cristianesimo. Transcrição da palestra proferida em 18 de maio de 2007.

5 "con le dottrine gnostiche la discussione tocca i grandi temi del cristianesimo".
} 
uma vez que esta função sugere os limites das analogias. No entanto, conforme afirmado anteriormente, a Encarnação traz à tona, de maneira mais contundente, a tensão entre a impassibilidade da transcendência e o envolvimento na experiência humana propriamente dita.

O primeiro modelo destinado a dissolver essa tensão conferiu aos sofrimentos de Cristo um status de aparência. Os proponentes desta "solução" foram os docetistas, para os quais Jesus não possuía corpo humano real, mas aparente e, embora tivesse passado por experiências humanas, não foi afetado por elas. Desta forma, a função do conceito da impassibilidade divina no pensamento docetista foi negar o envolvimento do divino nas experiências humanas feitas por Jesus.

Gavrilyuk acredita que, não obstante os limites da proposição docetista, eles formularam a pergunta fundamental: que tipo de experiência humana, descrito nos evangelhos, poderia ser atribuído a Jesus de maneira digna daquele que veio do alto?

O segundo modelo que buscou resolver a tensão presente na Encarnação foi proposto pelos arianos e, basicamente, retirou a divindade do Verbo, colocando-o como criatura singular. O Filho não seria imutável e impassível como o Pai. A lógica ariana se resumia da seguinte forma: o divino não pode sofrer, o Verbo sofreu, portanto não pode ser divino. Diante da dificuldade soteriológica implicada neste raciocínio, o esquema ariano sublinhou que o Verbo deveria ser um homem como nenhum outro, mas ao mesmo tempo, um homem como qualquer outro, capaz de sofrer. Desta forma, a função desempenhada pela impassibilidade divina na defesa ariana consistiu em evitar que Deus fosse implicado, de maneira direta, nas limitadas e imperfeitas experiências humanas.

A terceira resposta ao drama do sofrimento na Encarnação foi defendida por Nestório e apontava para a existência de dois sujeitos distintos no que se refere às ações divinas e experiências humanas. A impassibilidade divina no caso nestoriano teve função semelhante à mencionada quanto ao esquema ariano. Tal era a preocupação em proteger o divino de qualquer espécie de "contaminação" com a existência humana, que era preciso marcar uma clara distinção entre os sujeitos na Encarnação. Desta forma, o sofrimento na Encarnação afetou apenas o humano assumido pelo Logos, não o Logos divino.

À semelhança do que ocorreu com a experiência gnóstica - na qual os Padres tiveram que resguardar a noção de impassibilidade divina - o pensamento teológico avançou ao responder aos desafios apresentados pelos três modelos expostos. Em oposição ao modelo docetista, os Padres trataram de 
evidenciar a impassibilidade divina como qualificador apofático compatível com a participação direta de Deus na criação. A defesa enfática da realidade e do paradoxo da Encarnação tinha em mente os oponentes docetistas aos quais se endereçava. Portanto, os Padres ressaltaram o fato de Cristo ter passado pelo sofrimento, porém as implicações de tal experiência para Deus ainda precisavam ser esclarecidas. Qual teria sido o alcance dos sofrimentos humanos sobre a natureza divina?

É possível perceber nos confrontos posteriores que cada embate terminou por conduzir a tensão dialética a um nível mais elevado.

Com relação ao enfrentamento da questão ariana, é importante ressaltar, inicialmente, que ela representou um dos catalisadores da cristologia. A Tradição reforçou a divindade de Cristo como requisito necessário à salvação e o fato de que, em Cristo, houve a participação redentora de Deus junto à sua criação. A reação aos arianos enfatizou o status divino de Cristo, e isto contribuiu para acentuar ainda mais a tensão entre sua natureza divina e os sofrimentos terrenos por ele experimentados. A pergunta pelo envolvimento de Deus na experiência humana do Filho, também ganhou intensidade extra.

A oposição aos dois primeiros modelos sugeriu que nem a negação do sofrimento humano do Filho, nem a supressão de sua natureza divina, constituíam opções aceitáveis para lidar com a tensão causada pela defesa patrística do sofrimento impassível na Encarnação. Portanto, o terceiro modelo seguiu uma proposta diferente mediante uma clara demarcação entre dois sujeitos na encarnação, porém, tal proposição se mostrou igualmente insuficiente. $\mathrm{O}$ combate à teologia dos dois sujeitos destacou a figura de Cirilo de Alexandria que, mesmo sob acusação de theopatheia por parte de Nestório, expôs o perigo das implicações envolvidas na atribuição do sofrimento apenas a uma das naturezas. A presença do sofrimento somente na natureza humana colocava em risco a noção do envolvimento de Deus no mundo.

$\mathrm{O}$ escudo protetor da impassibilidade divina teria sido tocado pelo sofrimento do Filho? Se sim, em que medida? Se não, em que sentido o Filho sofreu? A próxima seção descreve a proposta de Cirilo seguida da consideração de suas contribuições para o debate e o desenvolvimento do pensamento teológico.

\section{A proposição de Cirilo de Alexandria: manutenção do paradoxo}

Diante do hino cristológico de Filipenses 2.5-11, Orígenes já havia expressado um paradoxo que seria desenvolvido dois séculos depois: "Aquele 
que estava na forma de Deus achou por bem estar na forma de servo; embora fosse imortal, morre, e o impassivel sofre, e o invisivel é visto" .

O referido hino tornou-se, na visão de Gavrilyuk, o ponto de partida de Cirilo ${ }^{7}$ para a compreensão da Encarnação. Apenas um sujeito divino - e não dois como parecia sugerir Nestório- sujeitou-se, voluntariamente, às restrições próprias da experiência humana. Desta forma, o sujeito do autoesvaziamento sublinhado na passagem de Filipenses, era Deus, o Verbo encarnado, uma vez que, só poderia passar pela experiência do esvaziamento aquele no qual habitava a plenitude de Deus.

A afirmação joanina "kai o I ogoj sarx egeneto" (João 1.14), segundo Cirilo, implicava no fato do Logos ter assumido uma alma e um corpo, não por participação, contudo, sem envolver mudança de qualquer espécie por parte da divindade. Em sua análise exegética da expressão utilizada pelo evangelista João, Cirilo defendeu que Jesus não poderia ser considerado como um simples homem no qual Deus habitou, pois tal entendimento acabaria por esvaziar o sentido da Encarnação. O significado do termo Encarnação estava no fato de Jesus ter se tornado como nós, mesmo que ainda permanecesse acima de nós.

Quanto à relação entre a natureza humana e divina em Cristo, Cirilo afirmou que a primeira era aperfeiçoada pela segunda. Aquilo que o Logos realizara na humanidade de Jesus - ou seja, sua elevação - também estaria reservado a toda a humanidade. A carne não afeta o Logos, é este que afeta a carne.

Cirilo havia constatado que era possível encontrar nos evangelhos relatos de ações divinas e humanas atribuídas a Jesus e, sem abrir mão da ortodoxia e da defesa da impassibilidade divina, ele defendeu que a natureza divina em Cristo não passou pelo sofrimento, mas Cristo sofreu na carne. Cumpre observar que Cirilo, ao empregar o termo sarx, incluiu a alma humana racional.

Desta forma, ao se deparar com as informações acerca das emoções atribuídas a Jesus, Cirilo explicou que elas foram superadas pelo Logos. O medo que tocou a natureza humana de Jesus, por exemplo, foi controlado pelo Logos de forma a não permitir que Jesus fosse por ele dominado. A alma racional possuía

\footnotetext{
6 "Alors qu'il était de condition divine, Il a daigné être de condition servile; alors qu'il est immortel, il meurt, impassible il souffre, invisible il est vu”. ORIGÉNE. Homélies sur le lévitique. Trad. Marcel Borret. Paris: Cerf, 1981 (Sources Chrétiennes 286) p.121, 123.

${ }^{7}$ No entanto, O'KEEFE, John, Impassible Suffering? Divine passion and fifth-century christology, Theological Studies, 58, 1997, acredita que Cirilo tenha partido do Cristo "econômico" encontrado na Escritura e também na Igreja.
} 
conhecimento e consciência dos sofrimentos pelos quais o corpo passava, mas não era por eles afetada, a divindade permanecia impassível.

Assim, Cirilo sugere que a sujeição das emoções ao Logos implicava em uma vitória que se estendia à natureza humana, elevando-a, ou seja, a ação do Logos encerrava um propósito salvífico. Portanto, o sofrimento voluntariamente assumido pelo Verbo produziu, conforme os escritos de Cirilo, impactos soteriológicos significativos.

Cirilo argumentou em seus escritos que as experiências pelas quais Cristo passou, quer tenham sido de medo ou aflição, representam para a natureza humana, libertação. Não haveria para a humanidade qualquer esperança de libertação deste tipo de experiência se o próprio Cristo não as tivesse sofrido e superado. Portanto, os sentimentos experimentados não exerceram domínio sobre Cristo e este fato acena para nós como libertação e expectativa de transformação.

É importante ressaltar que Cirilo se preocupou em apresentar critérios para a utilização de alguns termos presentes em seus argumentos. Diante das acusações de theopatheia, explicou que, ao atribuir sofrimento e emoções humanas a Deus, não falava da divindade encarada fora dos limites do autoesvaziamento, o sujeito era Deus na carne. Desta forma, afirmações do tipo "Deus sofreu" só teriam legitimidade teológica na medida em que não fossem deslocadas da compreensão de que seu sujeito não se referia a Deus fora da moldura da Encarnação.

Cirilo não atribuiu os sofrimentos diretamente à natureza do Verbo, mas reconheceu que as duas naturezas são divididas tendo em vista apenas o âmbito teórico, pois em Cristo há apenas um sujeito: o Verbo feito carne que não sofreu na natureza divina.

A noção de impassibilidade divina foi mantida e defendida por Cirilo, sem este pressuposto o Verbo não poderia ser divino. Porém, Cirilo insistiu no fato da experiência do sofrimento ter atingido a carne sem, contudo, aceitar que tal defesa o obrigasse a afirmar que Deus sofre.

Embora não tivesse esclarecido o "como" referente ao sofrimento impassível do Verbo, Cirilo recorreu ao emprego de uma imagem concreta para expressá-lo. Ele se valeu da analogia do ferro (humanidade de Jesus) aquecido pela chama (Logos), em tal situação a chama não perde calor ao atuar sobre o ferro, porém este é alterado.

Ao se referir à (im)passibilidade divina na Encarnação, Cirilo tomou o cuidado - já destacado anteriormente - de qualificar o uso do termo, ou seja, ele defendeu a impassibilidade no sentido de salvaguardar o fato de ser verdadeiramente Deus aquele que se fez carne. Desta forma, Cirilo se serviu 
do conceito como indicador da transcendência e irredutibilidade divina. Por outro lado, admitir uma passibilidade qualificada, isto é, não atribuída ao Verbo indiscriminadamente, significava resguardar o fato de Deus ter se submetido às condições limitantes da Encarnação.

O Verbo de Deus é, sem dúvida, impassível em sua própria natureza e ninguém é louco o bastante para imaginar que a natureza transcendente seja capaz de sofrer; porém, exatamente pelo fato de ter se tornado homem, fazendo sua a carne da Santa Virgem, mantemo-nos fiéis aos princípios do plano divino, sustentando que aquele que, como Deus, transcende o sofrimento, sofreu humanamente em sua carne. ${ }^{8}$

Portanto, é importante reforçar que a impassibilidade divina em Cirilo não era incompatível com a participação de Deus no mundo. Cirilo esteve, no entanto, consciente da tensão teológica que sustentava em sua afirmação paradoxal: "vemos em Cristo o insólito e estranho paradoxo do senhorio em forma de servo e da glória divina em pequenez humana".

O Padre alexandrino se empenhou em permanecer fiel tanto ao relato bíblico quanto à Tradição acerca da impassibilidade divina e, para tanto, não hesitou em recorrer a uma linguagem paradoxal para expressar em que sentido pode-se afirmar que o Verbo encarnado sofreu. Porém, em que medida, a insistência de Cirilo na defesa do paradoxo pode ter iluminado o pensamento teológico sobre a Encarnação? As considerações da seção seguinte pretendem oferecer algumas pistas sobre sua contribuição.

\section{Considerações finais sobre o paradoxo da Encarnação: algo a ser resolvido ou celebrado?}

É preciso manter em mente que tanto Cirilo de Alexandria quanto seus antagonistas antioquenos concordavam com a teologia nicena. Então, o que

\footnotetext{
8 "God's Word is, of course, undoubtedly impassible in his own nature and nobody is so mad as to imagine the all-transcending nature capable of suffering; but by very reason of the fact that he has become man, making flesh from the Holy Virgin his own, we adhere to the principles of divine plan and maintain that he who as God transcends suffering, suffered humanly in his flesh." Cyril, De symbol, trad. Wickham, Cyril, 123 apud Gavrilyuk, 2004, p.161.

9 "Et dans Le Christ on trouvait cet insolite, cet étrange paradoxe: la Seigneurie en la forme d'un serviteur, la gloire divine dans la petitesse humaine”. CYRILLE D'ALEXANDRIE. Deux dialogues christologiques. Trad. G. M. de Durand. Paris: Cerf, 1965 (Sources Chrétiennes 97) p. 431,433.
} 
estava em jogo no debate sobre a Encarnação - que já traz consigo a mensagem paradoxal do Verbo que se fez carne - a ponto de suscitar acaloradas controvérsias? É possível observar que existe um tema que logo salta aos olhos: a preservação do conceito de impassibilidade divina. Esta preocupação teológica, sobretudo no que se refere ao tratamento do tema da Encarnação, foi mantida, mas a tensão resultante do paradoxo tornou-se cada vez mais intensa ao longo dos debates. Como explicar o Verbo encarnado sem atribuir ao próprio Deus o sofrimento e outras questões pertencentes ao âmbito humano e limitado? As tentativas de resolver a questão mostraram-se insatisfatórias, no entanto, fizeram parte da busca por uma resposta, por uma linguagem que explicasse a Encarnação e, ao mesmo tempo, zelasse pela integridade da transcendência.

Cirilo, embora mantivesse a posição tradicional, contribuiu para o avanço do debate ao sugerir que os termos não poderiam ser utilizados indiscriminadamente, era preciso levar em conta alguns limites. Em primeiro lugar, o termo "impassibilidade" não era incompatível com o envolvimento de Deus no mundo, inclusive no evento da Encarnação, aquele que se encarnou era verdadeiramente Deus. Além disto, a atribuição do sofrimento humano não poderia ser feita diretamente à divindade fora da moldura da Encarnação. Desta forma, a paradoxal frase ciriliana "o impassível sofreu" pode ser compreendida apenas diante de tais critérios, ou seja, Deus na carne experimentou os sofrimentos da experiência humana. E a esta noção, Cirilo acrescentou o fato dessas limitações terem sido assumidas voluntariamente com propósitos salvíficos e, colocando em relevo a plena participação de Deus junto à criação.

No entanto, os argumentos propostos por Cirilo apontavam para a dificuldade de encontrar um modelo adequado para descrever e explicar o "como" envolvido no evento da Encarnação. É preciso reconhecer que a elaboração ciriliana estava aberta ao desenvolvimento posterior, ainda recorria ao mundo imediato, tanto ao usar categorias bíblicas, quanto ao usar imagens concretas para explicar o sofrimento impassível, não ascendeu ao campo das relações que descrevem aquilo que não pode ser diretamente observado na experiência e estão presentes no mundo mediado pelo significado.

Mesmo com a defesa do paradoxo, Cirilo não resolveu totalmente a questão, e isto gerou uma lacuna que foi explorada por seus oponentes, sobretudo por Nestório. No entanto, trouxe alguma luz ao debate. Gavrilyuk defende que a ausência de resolução do paradoxo teve como motivação a busca por um relato do envolvimento divino característico da fé cristã. Por outro lado, Hallman percebe algum avanço na defesa do paradoxo, porém o considera insuficiente: 
Sua afirmação não é "muito iluminadora" porque não explica, de maneira satisfatória, como o Logos é impassível e, simultaneamente, capaz de sofrer. Embora o paradoxo de Cirilo expresse o caráter teológico distintivo da visão cristã de Deus comparada à de Platão e Aristóteles, não se encontrava disponível a conceptualização filosófica para expressar tal entendimento da Encarnação. ${ }^{10}$

Hallman encara positivamente a oposição nestoriana, destacando-lhe o valor na medida em que demandou racionalidade e coerência por parte de Cirilo:

A crença na descida de Deus em Jesus de Nazaré expressa a essência da fé cristã e precisa ser preservada com vistas à manutenção da plenitude desta fé. Desenvolver a questão teológica da passibilidade divina é algo intimamente relacionado à defesa inteligível da confissão cristã. Tal confissão pode, de maneira apropriada, começar com um paradoxo do sofrimento impassível, mas deve, em última instância, fazer uso de categorias e distinções racionais sistemáticas para expressá-la. Esta é a importância da crítica de Nestório que, em nome do espírito da teologia racional, exigiu coerência. ${ }^{11}$

Contudo, Cirilo defendeu o paradoxo da Encarnação expressando-se em uma linguagem igualmente paradoxal, mesmo consciente de que isto daria margem à frustração dos interessados em dissolver a tensão, e às críticas ferrenhas dos que viam em sua defesa a perigosa introdução do sofrimento na divindade.

O Padre alexandrino não encarou o paradoxo como um problema a ser resolvido, pelo contrário, era algo a ser celebrado como elemento característico da doutrina cristã da encarnação. Cirilo abraçou a tensão e não a encarou como uma questão de "uma coisa ou outra", mas "de uma coisa e outra". A

10 "His statement is 'not very illuminating' because it does not satisfactorily explain how the Logos is impassible and simultaneously able to suffer. Although the paradox of Cyril expresses the theological distinctiveness of the Christian view of God compared to those of Plato and Aristotle, philosophical conceptuality to express this incarnational understanding was not available" HALLMAN, Joseph M. The seed of fire: divine suffering in Christology of Cyril of Alexandria and Nestorius of Constantinople. Journal of Early Christian Studies 5.3 (1997), p.8.

11 "Belief in the descent of God in Jesus of Nazareth expresses the essence of Christian faith and needs to be preserved to adhere to the fullness of that faith. Working out the theological question of divine passibility is intimately related to the intelligible defense of the Christian confession. This confession may appropriatelly begin with a paradox of impassible suffering, but must ultimately make use of rational systematic categories and distinctions to express it. And this is the importance of the critique of Nestorius who in the spirit of rational theology, demanded consistency." (HALLMAN, 1997, p.12). 
tensão não precisava ser resolvida, não era preciso temer a linguagem, aparentemente teopasquita, envolvida na defesa do paradoxo, segundo O'Keefe, Cirilo era um exegeta, imerso na linguagem bíblica, nada mais natural que seu conhecimento das Escrituras permeasse seus argumentos.

A narrativa bíblica ofereceu o substrato a partir do qual a defesa de Cirilo foi construída. O sofrimento impassível é uma afirmação tão paradoxal quanto as categorias bíblicas nas quais Cirilo escolheu se apoiar. As afirmações paradoxais presentes no Novo Testamento tais como a declaração das Bem-aventuranças no Sermão do Monte, ou quando o apóstolo Paulo diz que sua força está em suas fraquezas (2 Co 12.10), e o próprio evento da Encarnação (Jo 1.14) ressaltam a transformação - e o propósito salvífico - que Deus efetua ao se envolver na experiência humana.

Gavrilyuk defende que o paradoxo é um elemento que faz parte do canon, e Cirilo se destaca entre os teólogos patrísticos por ter percebido que é exatamente neste paradoxo que se encontra o cerne do evangelho. O'Keefe completa: “ele compreendeu que tais narrativas [bíblicas] ofereciam a gramática do discurso cristão, e que eram a elas que outras convicções, tais como a impassibilidade de Deus, deveriam estar sujeitas" 12 . Desta forma, a obra de Cirilo testemunha que o Padre alexandrino não recuou diante das implicações envolvidas na descrição e explicação do evento da Encarnação, pelo contrário, ousou defendê-las a partir das categorias bíblicas e, assim, prestar sua contribuição ao desenvolvimento do pensamento teológico cristão.

Cirilo de Alexandria nos deixa a lição de que o fazer teológico não consiste na resolução de uma equação matemática ou silogismo lógico, mas em contemplar o mistério. Os conceitos são importantes para a exposição e para a explicitação racional do tema, contudo, é preciso que estejam abertos ao desenvolvimento, cientes de que a realidade os ultrapassa.

\footnotetext{
12 "he understood that those narratives provide the grammar of Christian discourse, and that to those narratives other convictions, for example the impassibility of God, should be subordinate" (O’KEEFE, 1997, p.60). É preciso lembrar que, ao contrário do pensamento de Gavrilyuk, O’Keefe acredita que a impassibilidade divina era um conceito filosófico grego assimilado pelos Padres e que Cirilo optara por dar primazia à narrativa bíblica. Para O’Keefe os pressupostos filosóficos e as narrativas bíblicas constituíam as opções disponíveis para a teologia patrística, portanto, os conflitos surgiam quando estas alternativas não se harmonizavam.
} 


\section{Referências Bibliográficas}

CYRILLE D'ALEXANDRIE. Deux dialogues christologiques. Trad. G. M. de Durand. Paris: Cerf, 1965 (Sources Chrétiennes 97) p. 431, 433.

GAVRILYUK, Paul. The suffering of the impassible God: the dialects of patristic thought. New York: Oxford University Press, 2004.

HALLMAN, Joseph M. The seed of fire: divine suffering in christology of Cyril of Alexandria and Nestorius of Constantinople. Journal of Early Christian Studies 5.3 (1997).

JOÃO PAULO II, Papa. Carta apostólica Salvifici Doloris. São Paulo: Edições Paulinas, 1988.

LETTIERI, Gaetano. Deus patiens: l'essenza cristologica dello gnosticismo. Lo gnosticismo, le sue origini cristiani e la sua importanza nello sviluppo teologico del cristianesimo. Transcrição da palestra proferida em 18 de maio de 2007. Disponível em: <http://www.gliscritti.it/approf/2007/ conferenze/lettieri030607.htm>. Acesso em 09 de agosto de 2012.

O'KEEFE, John J. Impassible suffering? Divine passion and fifth-century christology. Theological Studies 58 (1997) p. 39-60.

ORIGÉNE. Homélies sur le lévitique. Trad. Marcel Borret. Paris: CERF, 1981 (Sources Chrétiennes 286) p. 121, 123.

\section{Karina Andrea Pereira Garcia Coleta}

Graduada em Ciências Econômicas pela PUC Minas

Mestranda em Teologia pela Faculdade Jesuíta de Filosofia e Teologia - FAJE Especialista em Estudo da Tradução pela Universidade Gama Filho - UGF Instituição Financiadora: Capes E-mail: karinacoleta@gmail.com

Recebido em 12/11/2012 Aprovado em 30/04/2013 